\title{
Integration of Post Abortion Care Package in the Activity of 56 Health Facilities by the Burkina Faso Society of Obstetricians and Gynecologists (SOGOB)
}

\author{
Sibraogo Kiemtoré1,2, Hyacinthe Zamané1,2, Yobi Alexis Sawadogo',2, \\ Charlemagne Marie Ouédraogo1,2, Dantola Paul Kaïn1,2, Abdoule Azize Diallo1, \\ Issa Ouédraogo ${ }^{1,3}$, Adama Dembélée,5, Ali Ouédraogo ${ }^{1,2}$, Blandine Thiéba ${ }^{1,2}$, \\ Jean Lankoandé1,2 \\ ${ }^{1}$ Department of Obstetrics and Gynecology, Yalgado Ouedraogo Teaching Hospital in Ouagadougou, \\ Ouagadougou, Burkina Faso \\ ${ }^{2}$ Unity of Training and Research in Health Sciences (UFR/SDS), University of Ouagadougou, Ouagadougou, \\ Burkina Faso \\ ${ }^{3}$ Department of Obstetrics and Gynecology, Centre Hospitalier Régional de Ouahigouya, Ouahigouya, \\ Burkina Faso \\ ${ }^{4}$ Department of Obstetrics and Gynecology and Reproductive Health, Sanou Sourou Teaching Hospital, \\ Bobo-Dioulasso, Burkina Faso \\ ${ }^{5}$ Higher Institute of Science Health, Polytechnic University of Bobo-Dioulasso, Bobo-Dioulasso, Burkina Faso \\ Email: s3kiemtore@yahoo.fr
}

Received 10 June 2016; accepted 5 July 2016; published 8 July 2016

Copyright (C) 2016 by authors and Scientific Research Publishing Inc.

This work is licensed under the Creative Commons Attribution International License (CC BY).

http://creativecommons.org/licenses/by/4.0/

(c) (i) 0 pen Access

\section{Abstract}

Introduction: This article is an analysis of post-abortion care in $\mathbf{5 6}$ health facilities after their capacity building by the Burkina Faso Society of Obstetricians and Gynecologists (SOGOB). Patients and Methods: In 2012, with funds from Safe Abortion Action Fund, the SOGOB trained care providers and equipped 56 health facilities for post abortion care. Statistical data on the management of incomplete abortions after the capacity building were analyzed. The significance level was set at 0.05. Results: There were 6316 cases of abortion that have been managed in 56 health facilities. The evacuation of the uterine contents for incomplete abortion has been provided to 6167 patients. Manual vacuum aspiration (MVA) and misoprostol were used respectively in $69.4 \%$ and $26.9 \%$ of cases to evacuate uterine content. Post-treatment complications were $1.8 \%$ for MVA and $0.9 \%$ for misoprostol $(p=0.004)$. MVA's complication rate in the health facilities of the $1^{\text {st }}$ level of care $(1.7 \%)$ was not different from the third level of care $(1.2 \%)$ with $p=0.21$. A modern method

How to cite this paper: Kiemtoré, S., Zamané, H., Sawadogo, Y.A., Ouédraogo, C.M., Kaïn, D.P., Diallo, A.A., Ouédraogo, I., Dembélé, A., Ouédraogo, A., Thiéba, B. and Lankoandé, J. (2016) Integration of Post Abortion Care Package in the Activity of 56 Health Facilities by the Burkina Faso Society of Obstetricians and Gynecologists (SOGOB). Open Journal of Obstetrics and Gynecology, 6, 457-462. http://dx.doi.org/10.4236/ojog.2016.68061 
of contraception was provided after abortion to $65.7 \%$ of the patients. In addition to the post abortion care, $7.3 \%$ of the patients received other reproductive health services. The community was involved in the development process of post abortion care in the facilities of the first level of care. Conclusion: The support of health facilities by SOGOB has provided post abortion care to thousands of women with little complications. Given the good results, an extension to other health facilities is desirable.

\section{Keywords}

Post-Abortion Care, MVA, Misoprostol, Family Panning, Burkina Faso

\section{Introduction}

In Burkina Faso, maternal mortality has been estimated at 341 per 100,000 live births in 2010 [1]. In the same year, 24\% of women of reproductive age had unmet need for family planning [2]. In Sub-Sahara Africa where Burkina Faso is located, abortion is a public health problem. Indeed this region concentrates $77 \%$ of 193,000 deaths due to abortions which occurred between 2003 and 2012 in the world [3]. The huge number of patients with complications of abortion seeking care in health facilities had led to the establishment of post abortion care (PAC) in Burkina Faso in 1998. However, coverage in post abortion care in the countries remained insufficient. To help fill this gap, the Burkina Society of Obstetricians Gynecologists (SOGOB), with funds from Safe Abortion Action Fund (SAAF), helped 56 health facilities (sites of SAAF project) of countries in the integrated management of abortion cases. The support included the strengthening of skills of health care providers in PAC and the provision of equipment and consumables necessary for sites. Ideal PCA includes counseling, emergency treatment of complications and evacuation of uterine contents (by MVA or $400 \mu \mathrm{g}$ of misoprostol by sublingual route), post-abortion contraception, reference to the other services of reproductive health, and involvement of the community. This article is an analysis of the management of cases of abortion in these sites.

\section{Patients and Methods}

A statistical analysis of treated abortion's cases in 56 health facilities was done. These health facilities are the sites where the project was developed and implemented by the SOGOB. The study population consisted of all cases of abortion occurred in the first trimester and managed between 1 July 2012 and 30 July 2014, which is the implementation period of the project. The 56 sites were composed of two teaching hospitals (tertiary level care), 9 regional hospitals ( ${ }^{\text {nd }}$ level of care), 15 medical centers with a surgical unit ( $2^{\text {nd }}$ level $1^{\text {st }}$ level care) and 30 health centers and social promotion (primary level of the $1^{\text {st }}$ level of care).

The uterine evacuation methods advocated by SOGOB were manual vacuum aspiration (MVA) and misoprostol use. The fees for MVA procedure was subsidized at $80 \%$ and the patient paid 3600 FCFA $(\approx 6$ dollars USA). The uterine evacuation using misoprostol was offered for free. For each patient, identity, socio-demographic, obstetric history, age of pregnancy, the type of abortion, complications, the evacuation method of uterine contents, and data on family planning were recorded. Data were anonymously collected and transmitted monthly to the headquarters of the SOGOB. The data were entered and analyzed using the software Epi 7.1.5 CDC Atlanta [4]. The chi-square test and odds ratios were used for comparisons. The significance level was set at $5 \%$.

\section{Results}

\section{Frequency}

In total, 6316 cases of abortion meeting our selection criteria were compiled in the 56 SAAF project centers during the study period. Of these, 1060 (16.8\%) were managed in the health centers, 2015 (31.9\%) in the Medical Centers with a surgical unit, 1956 (31.0\%) in the regional hospitals, and 1195 (18.9\%) in the teaching hospitals. The proportion of admission for induced abortion was $13 \%$. 


\section{Managed Cases}

\subsection{Counseling}

The counseling was performed in all the patients. It was about the treatment of complications, the methods of evacuation of uterine contents as well as family planning method.

\subsection{Emergency Treatment of Complications and Evacuation of the Uterine Contents}

Resuscitation was performed in 321 (5.2\%) cases including 98 blood transfusions. An evacuation of the uterine contents was performed in 6167 patients. MVA was the most commonly used method (Table 1).

Misoprostol was more used in the health center than in the teaching hospitals ( $45 \%$ vs. $14.8 \%$; $p=0.004)$. The rate of complications requiring treatment was higher when MVA was used (1.8\%: 77/4281) than when misoprostol was used $(0.9 \%$ : $15 / 1662), \mathrm{p}<0.001$. The 15 cases of misoprostol dehydration complications were due to vomiting and/or diarrhea with or without fever. These cases have all been treated successfully symptomatic way (rehydration with antiemetic and antidiarrheal). The occurrence of complications with the use of MVA was not associated with the health facility type (Table 2). These complications of MVA were pelvic infection (1.4\%: 58/4281) and uterine perforation (0.6\%: 26/4281). They have been successfully treated with antibiotics and uterotonic.

\subsection{Post-Abortion Contraception}

Counseling on family planning was performed in 95.8\% (6052/6316) of the cases. A modern method of contraception was adopted by $65.7 \%$ (4148) of the patients. The majority (72.06\%) of the patients have adopted the combined oral contraceptive pill as a contraceptive method (Figure 1).

\subsection{Other Services of Reproductive Health}

The patients received other services from the reproductive health (RH) in $7.3 \%$ of cases (460/6311). The other reproductive health services were dominated by the screening and treatment of precancerous lesions of the cervix (Table 3).

\subsection{Involvement of the Community}

To ensure better perception by the population and the sustainability of post-abortion care in health facilities, the

Table 1. Distribution of uterine evacuation methods depending on the types of health facilities.

\begin{tabular}{cccc}
\hline Health facilities & MVA n (\%) & Misoprostol n (\%) & Digital evacuation n (\%) \\
\hline Health centers & $539(50.8)$ & $477(45.0)$ & $44(4.2)$ \\
Medical centers & $1515(73.8)$ & $461(22.5)$ & $77(3.8)$ \\
Regional hospital & $1206(65.0)$ & $546(29.4)$ & $103(5.6)$ \\
Teaching hospitals & $1021(85.2)$ & $178(14.8)$ & $0(0.0)$ \\
Total & $4281(69.4)$ & $1662(26.9)$ & $224(3.6)$ \\
\hline
\end{tabular}

Table 2. Post MVA complications according to type of health facility.

\begin{tabular}{|c|c|c|c|c|c|}
\hline \multirow[t]{2}{*}{ Health facility } & \multicolumn{2}{|c|}{ Complications post MVA } & \multirow[t]{2}{*}{ Total } & \multirow[t]{2}{*}{ Odds-ratio [IC 95\%] } & \multirow[t]{2}{*}{$\mathrm{p}$} \\
\hline & $\mathrm{n}$ & $(\%)$ & & & \\
\hline Teaching hospital & 12 & $(1.2)$ & 1021 & 1 & \\
\hline Regional hospital & 13 & (1.1) & 1206 & $1.09[0.50-2.40]$ & 0.83 \\
\hline Medical centers & 21 & $(1.4)$ & 1515 & $0.85[0.41-1.73]$ & 0.65 \\
\hline Health centers & 9 & $(1.7)$ & 539 & $0.70[0.29-1.67]$ & 0.42 \\
\hline
\end{tabular}




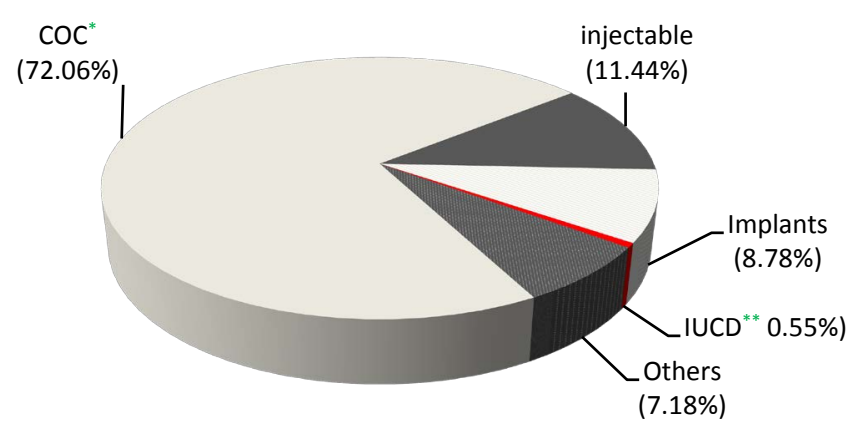

Figure 1. Distribution of patients according to the chosen method of contraception $(n=4148)$. ${ }^{*}$ Combined oral contraceptive; *** Intra-uterine contraception device.

Table 3. Other reproductive health care received of the patients.

\begin{tabular}{ccc}
\hline Other services reproductive health & $\mathrm{n}$ & $\%$ \\
\hline Treatment of STI & 45 & 9.8 \\
Management of subfertility & 70 & 12.8 \\
Screening of precancerous lesions of the cervix & 256 & 77.4 \\
Total & 371 & 100.0 \\
\hline
\end{tabular}

committees managing the health facilities whose members are from the community were involved in the process. Post-abortion care was the subject of discussion in all health facilities in the first level of care (health centers and medical centers). The MVA devices of two health facilities were renewed by their management committee.

\section{Discussion}

There were 6316 patients who received post-abortion care in 56 health facilities project sites including $13 \%$ of cases of illegal induced abortion. Nationally, 7.4\% (1964/26518) of cases of abortions managed in all health facilities in the country in 2012 were illegal induced abortion [5]. A higher proportion (86.7\%) was found by Mayi-Tsonga and al at Libreville's hospital in Gabon [6]. The lower proportion found in our study is probably due to underreported cases. Indeed, in Burkina Faso, abortion is not allowed by law [7] and especially it is not accepted by society. Therefore, patients who do illegal abortion tend to hide the nature of their abortion because of fear of prosecution and stigmatization.

The most used evacuation methods of the uterine contents were the MVA and misoprostol administration. Providers in health centers have used misoprostol more than in the tertiary level (45\% for health centers vs. $14.8 \%$ in teaching hospitals; $\mathrm{p}=0.004$ ).

In Burkina Faso, the methods of evacuation of uterine contents have evolved over time. Before 1992, the evacuation of the uterine contents for incomplete abortion was performed either by dilation and curettage or by digital removal. These methods have been replaced by MVA with the implementation of post abortion care in 1992. However, MVA was only used in the teaching hospitals, regional hospital and medical centers. Later in 2007, a pilot phase of the use of misoprostol in the management of incomplete abortions proved the efficacy, safety and acceptability of the drug in the context of Burkina Faso [8]. The efficacy and safety of misoprostol in the management of incomplete abortion have been proven by several studies [9]-[12]. Despite this evidence, the health authorities of Burkina Faso have long been reluctant to accept the introduction of this drug in the treatment of incomplete abortion.

The results of the SAAF pilot project provided some advocacy arguments that allowed, in 2015, the introduction of misoprostol in the package for management of abortion cases. The administration of misoprostol does not require special technical skills, so, it was used at all levels of health facilities. Complications related to its use $(0.9 \%)$ were fewer than those of MVA $(1.79 \%)$ with $\mathrm{p}<0.001$. Also, the rate of complications post MVA was not significantly different $(\mathrm{p}=0.21)$ in the health centers $(1.7 \%)$ from that of the teaching hospitals $(1.2 \%)$. MVA can be used at peripheral health facilities without increasing the risks, provided that care providers are 
trained. These results have encouraged SOGOB to expand the use of MVA and misoprostol in PAC to other health care facilities.

Post-abortion contraception helps break the cycle of unwanted pregnancy and induced illegal abortion [13] [14]. It is with this realization that the International Federation of Gynecology Obstetrics (FIGO) and the World Health Organization (WHO) advocate the integration of family planning in the post-abortion care [15]. In our study, counseling on family planning was performed in $95.8 \%$ of the patients. Out of these patients, $65.7 \%$ have adopted a family planning method. This rate appears to be higher however it is small, compared to the ideal which would like that all women adopt post-abortion's contraception method, for at least 6 months [16] [17]. One reason for this underperformance is the absence of integration of family planning in post abortion care, which SOGOB should help fulfill. Indeed, some health centers have no family planning service. As a matter of fact, prescription is often given to the woman so that she can go and pay the contraceptive product outside the health center. However, this state of fact does not allow to have information on real practice of post abortion contraception. In our study, the proportion of women who have adopted a long-acting method was low (8.78\% for contraceptive implants and $0.55 \%$ for the IUCD). The IUCD is known to be more effective than the pill and inject able contraceptives in preventing unwanted pregnancies [18]. In addition, among the modern reversible methods of contraception, IUCD has the best cost/efficiency.

A limitation of this study was the lack of data on late complications such as uterine synechia post MVA.

\section{Conclusion}

The intervention of the SOGOB has allowed the management of thousands of cases of abortion with little complications. Over a quarter of cases, the evacuation of the uterine contents was obtained by the administration of misoprostol. The frequency of complications was less important when using misoprostol than MVA. The extension of the capacity building in post abortion care to other health facilities is needed while putting special emphasis on the use of misoprostol. However, an awareness of the providers is reinforced to minimize the risk of diverted use of misoprostol. Two thirds of women have adopted modern contraceptive method after abortion, but the long-term acting methods have been used very little.

\section{Acknowledgements}

The SOGOB for permission to use the database.

\section{References}

[1] National Institute of Demography Statistics (2011) Demographic and Health Surveys and Multiple Indicators of 2010 in Burkina Faso. National Institute of Demography Statistics, Burkina Faso.

[2] Bankole, A., Hussain, R., Sedgh, G., Rossier, C., Kaboré, I. and Guiella, G. (2013) Unwanted Pregnancy and Induced Abortion in Burkina Faso: Causes and Consequences. Guttmacher Institute Press, New York.

[3] Say, L., Chou, D., Gemmill, A., Tunçalp, Ö., Moller, A.B., Daniels, J., et al. (2014) Global Causes of Maternal Death: A WHO Systematic Analysis. The Lancet Global Health, 2, e323-33. http://dx.doi.org/10.1016/S2214-109X(14)70227-X

[4] Center for Disease Control and Control (2015) Epi Info 7.1.5. http://wwwn.cdc.gov/epiinfo/7/

[5] Direction générale des études et des statistiques sectorielles du Ministère de la santé. Direction Générale de l' Information et des Statistiques Sanitaires (DGESS) (2013) Health Statistical Yearbook of 2012. DGESS, Ouagadougou.

[6] Mayi-Tsonga, S., Diallo, T., Litochenko, O., Methogo, M. and Ndombi, I. (2009) Prevalence of Illegal Abortions to Hospital in Libreville, Gabon. Bulletin de la Société de Pathologie Exotique, 102, 230-232.

[7] Ministry of Justice of Burkina Faso (1996) Penal Code of 1996 Burkina Faso. Sections 383 to 390.

[8] Dao, B., Blum, J., Thiéba, B., Raghavan, S., Ouédraogo, M., Lankoande, J., et al. (2007) Is Misoprostol a Safe, Effective and Acceptable Alternative to Manual Vacuum Aspiration for Postabortion Care? Results from a Randomised Trial in Burkina Faso, West Africa. BJOG, 114, 1368-1375. http://dx.doi.org/10.1111/j.1471-0528.2007.01468.x

[9] Blum, J., Winikoff, B., Gemzell-Danielsson, K., Ho, P.C., Schiavon, R. and Weeks, A. (2007) Treatment of Incomplete Abortion and Miscarriage with Misoprostol. International Journal of Gynecology \& Obstetrics, 99, S186-S189. http://dx.doi.org/10.1016/j.ijgo.2007.09.009

[10] Dah, T., Akiode, A., Awah, P., Fetters, T., Okoh, M., Ujah, I., et al. (2011) Introducing Misoprostol for the Treatment of Incomplete Abortion in Nigeria. African Journal of Reproductive Health, 15, 42-50. 
[11] Thieba, B., Ouattara, A.Z., Coral, A., Hassane, C., Clotaire, H., Dao, B., et al. (2012) Sublingual Misoprostol as FirstLine Care for Incomplete Abortion in Burkina Faso. International Journal of Gynecology and Obstetrics, 119, 166-169. http://dx.doi.org/10.1016/j.ijgo.2012.05.036

[12] Gatter, M., Cleland, K. and Nucatola, D.L. (2015) Efficacy and Safety of Medical Abortion Using Mifepristone and Buccal Misoprostol through 63 Days. Contraception, 91, 269-273. http://dx.doi.org/10.1016/j.contraception.2015.01.005

[13] Bongaarts, J. and Westoff, C.F. (2000) The Potential Role of Contraception in Reducing Abortion. Studies in Family Planning, 31, 193-202. http://dx.doi.org/10.1111/j.1728-4465.2000.00193.x

[14] Cleland, J., Bernstein, S., Ezeh, A., Faundes, A., Glasier, A. and Innis, J. (2006) Family Planning: The Unfinished Agenda. Lancet, 368, 1810-1827. http://dx.doi.org/10.1016/S0140-6736(06)69480-4

[15] Culwell, K.R., Vekemans, M., de Silva, U., Hurwitz, M. and Crane, B.B. (2010) Critical Gaps in Universal Access to Reproductive Health: Contraception and Prevention of Unsafe Abortion. International Journal of Gynecology and Obstetrics, 110, S13-S16. http://dx.doi.org/10.1016/j.ijgo.2010.04.003

[16] Conde-Agudelo, A., Rosas-Bermúdez, A. and Kafury-Goeta, A.C. (2006) Birth Spacing and Risk of Adverse Perinatal Outcomes. A Meta-Analysis. JAMA, 295, 1809-1823. http://dx.doi.org/10.1001/jama.295.15.1809

[17] USAID (2009) The Planning and Spacing of Pregnancy for Health (HTSP): Trainer's Guide. http://www.esdproj.org/site/DocServer/HTSP_TRG_FRENCH_Jan_27_2009.pdf?docID=2381

[18] Roberts, H., Silva, M. and Xu, S. (2010) Post Abortion Contraception and Its Effect on Repeat Abortions in Auckland, New Zealand. Contraception, 82, 260-265. http://dx.doi.org/10.1016/j.contraception.2010.03.003

\section{Submit or recommend next manuscript to SCIRP and we will provide best service for you:}

Accepting pre-submission inquiries through Email, Facebook, Linkedin, Twitter, etc A wide selection of journals (inclusive of 9 subjects, more than 200 journals)

Providing a 24-hour high-quality service User-friendly online submission system

Fair and swift peer-review system

Efficient typesetting and proofreading procedure

Display of the result of downloads and visits, as well as the number of cited articles

Maximum dissemination of your research work

Submit your manuscript at: http://papersubmission.scirp.org/ 